\title{
The associations of basic psychological needs and autonomous-related self with time perspective: The cultural and familial antecedents of balanced time perspective
}

\author{
Umit Akirmak $^{\mathrm{a}, *}$, Nursen Tuncer ${ }^{\mathrm{a}}$, Meliscan Akdogan ${ }^{\mathrm{a}}$, Orhan Batuhan Erkat ${ }^{\mathrm{b}}$ \\ ${ }^{\text {a }}$ Department of Psychology, Istanbul Bilgi University, Turkey \\ ${ }^{\mathrm{b}}$ Neuroscience Program at Bilkent University, Turkey
}

\section{A R T I C L E I N F O}

\section{Keywords:}

Time perspective theory

Basic psychological needs

Autonomous-related self

Self-determination theory

Subjective well-being

\begin{abstract}
A B S T R A C T
Time perspective develops from learning experiences pertaining to family and culture (Zimbardo \& Boyd, 1999), however no study specifically examined these factors. The present research examines cultural and familial processes influencing subjective time perceptions and balanced time perspective. Participants $(n=305)$ filled out a questionnaire that consisted of the Zimbardo Time Perspective Inventory (ZTPI), Basic Psychological Needs (BPN), Autonomous-Related Self (ARS), and Trait Anxiety Inventory. Balanced time perspective was operationalized as a derived score from the ZTPI factors, deviation from balanced time perspective (DBTP). BPN and ARS were related to the ZTPI factors and DBTP. A hierarchical regression analysis demonstrated that autonomy, competence, and ARS predicted DBTP. Finally, the results of two simple mediation analyses showed that the associations of ARS and BPN with trait anxiety were mediated by DBTP. It was suggested that social and familial restrictions disrupt the balance in time perspective leading to lower subjective well-being.
\end{abstract}

Time perspective (TP) involves subjective representations and evaluations of the past, present, and future, and has direct impact on goal pursuit, decisions, and behavior (Carstensen, Isaacowitz, \& Charles, 1999). Recent research has largely made use of Zimbardo Time Perspective Inventory (ZTPI; Zimbardo \& Boyd, 1999) in examining temporal orientations, and linked TP to personality (Kairys \& Liniauskaite, 2015), social relationships (Holman \& Zimbardo, 2009), and subjective well-being (Boniwell, Osin, Linley, \& Ivanchenko, 2010; Drake, Duncan, Sutherland, Abernethy, \& Henry, 2008). However, research on antecedent mechanisms of TP is limited. Time orientations are shaped by learning experiences involving interactions with family, religion, culture, and education (Keough, Zimbardo, \& Boyd, 1999); but this assumption was not empirically evaluated. Present study examined how cultural and familial factors are related to TP, and aimed to improve our understanding of mechanisms underlying subjective time orientations. For this purpose, basic psychological needs (BPN) and autonomousrelated self (ARS), as indicators of cultural and familial dynamics, were utilized.

\section{Time perspective}

According to Zimbardo and Boyd's (1999) time perspective theory,
TP is a non-conscious cognitive process that influences attitudes, decisions and behaviors. The ZTPI (Zimbardo \& Boyd, 1999) has five dimensions. Past Positive (PP) indicates a pleasant view of the past, but Past Negative (PN) indicates a sorrowful view of the past. Present Hedonistic $(\mathrm{PH})$ reveals a tendency to enjoy the present while ignoring risks or negative consequences. Present Fatalistic (PF) reveals a pessimistic view with hopelessness and perceived lack of control for future events. Future $(\mathrm{F})$ is associated with setting goals and delaying gratification.

All time orientations are utilized depending on the situational demands and habits. When a certain TP is consistently employed regardless of its fit with the situational demands, a temporal bias is assumed to develop. Such a bias acts as a dispositional style, and is dominantly used in interacting with the world and others. In contrast, flexibly switching among various temporal orientations characterizes the balanced time perspective (BTP; Boniwell \& Zimbardo, 2004). BTP has been linked to subjective well-being (Boniwell et al., 2010), mindfulness (Drake et al., 2008), happiness (Webster \& Ma, 2013), selfesteem, and romantic anxiety (Akirmak, 2014). Understanding the conditions under which BTP develops is crucial as it is strongly related to subjective well-being.

\footnotetext{
* Corresponding author at: Department of Psychology, Istanbul Bilgi University, Turkey.

E-mail address: umit.akirmak@bilgi.edu.tr (U. Akirmak).
} 


\section{Basic psychological needs}

A mechanism that presumably leads to BTP is satisfaction of basic psychological needs. According to self-determination theory (SDT; Deci \& Ryan, 2000) humans are inherently motivated to set and pursue their valued goals as long as three BPN are satisfied. The need for autonomy designates the perceived control of life and capability for voluntary actions; the need for competence reflects a general sense of self-efficacy; and the need for relatedness concerns relationships with the others. Satisfaction of these needs promotes optimal functioning, physical health, and subjective well-being, whereas thwarting them leads to development of need substitutes, ill-being, anxiety, and psychopathology (Baard, Deci, \& Ryan, 2004; Church et al., 2013; Deci \& Ryan, 2000; Ng et al., 2012; Ryan, Patrick, Deci, \& Williams, 2008).

Evidence suggests that BPN are innate and universal, but sensitive to cultural elements (Chen et al., 2015). Being innate and universal, and connected to optimal functioning and well-being, satisfaction of BPN is likely to be one of the mechanisms that sustains BTP. Because TP develops from experiences involving education, culture and family (Keough et al., 1999), it is possibly affected by the extent to which BPN are satisfied within these contexts. Environmental restrictions and difficulties in achieving need satisfaction may lead to temporal biases. Temporal biases involve overuse or underuse of temporal orientations and create rigid habitual response patterns that naturally disrupt the temporal balance. According to this view, BTP is directly related to the fulfillment of BPN. Although such a possibility was suggested by others, no study focused on this relationship.

\section{Autonomous-related self}

There is empirical support to the idea that early family interactions influence time orientations. For example, perceived parental attachment quality and BTP is related (Akirmak, 2014); and, parental interactions influence future orientation (Seginer, 2003). Furthermore, mother-child interaction quality is crucial for the development of delay of gratification abilities (Jacobsen, Huss, Fendrich, Kruesi, \& Ziegenhain, 1997), which can be conceptually linked to being high on future orientation and low on present orientation (Zimbardo \& Boyd, 1999).

We focused on a theory of self-construal that highlights the importance of the nature of parent-child interactions to investigate the role of family dynamics on TP. Kagitcibasi (1996) suggests that family dynamics have a strong influence on the development of various selfconstruals. According to her theory, self has two basic dimensions: agency and interpersonal distance. Agency concerns individual's volition in life choices and varies between autonomy and heteronomy; interpersonal distance concerns individual's connection with the others and varies between separateness and relatedness. Individual's position on these dimensions is affected by the extent to which parent-child interactions are lenient or restrictive, leading to differences in selfconstruals (Kagitcibasi, 2005). The present investigation focuses on the optimal self-construal, autonomous-related self (Kagitcibasi, 1996), which reflects individual's psychological connection to family (e.g., love, companionship, etc.) as well as his/her agency in making life choices.

While SDT posits that autonomy and relatedness are two separate dimensions driven from innate necessities (Deci \& Ryan, 2000), according to Kagitcibasi (2005) these are not innate needs, but products of parent-child relationship patterns. Parenting interactions that support autonomy together with psychological interdependence promote ARS. Findings show that ARS is associated with healthy functioning. ARS was positively associated with life satisfaction (Morsünbül, 2013) and psychological resilience (Yildirim, Yildirim, Otrar, \& Şirin, 2015), but negatively associated with depression (Morsünbül, 2013).

\section{Culture}

Individuals are embedded within larger social structures, and BPN are considered as sociocultural constructions that individuals learn through social processes (Buttle, 1989). Cultural environment imposes priorities on the values of needs, and "sets demands, obstacles, and affordances on them" (Chen et al., 2015; p.218). Thus, social-cultural factors shape individuals' motivation and behavior including the need satisfaction process (Deci \& Ryan, 2012).

Similarly, cultural attitudes and beliefs shape the familial processes, and, consequently, the self-construals developing through socialization (Kağıtçıbaşı, 2007). For example, findings show that high SES individuals living in the urban areas tend to show more endorsement of the ARS compared to individuals in the rural areas (Kagitcibasi \& Ataca, 2005). This pattern is explained by the changing social and economic conditions that moved the familial interaction patterns away from the family model of interdependence and the utilitarian value of the children, closer to the family model of psychological interdependence and psychological value of the children (Kagitcibasi, 2005).

\section{The current study}

Empirically and conceptually ARS is distinct from BPN, and thus it was decided useful to examine its associations with TP, as ARS and BPN reflect different aspects of socio-cultural influences. The main purpose of the present study was to examine the associations of BPN and ARS with the ZTPI dimensions and BTP. A prior study found a positive association between overall need satisfaction and BTP (Zhang, Howell, \& Stolarski, 2013), but BTP's associations with autonomy, competence, and relatedness remain to be explored. BTP was expected to have positive associations with these constructs and ARS. The present study also examined how BPN were associated with BTP, and the link between ARS and BTP, statistically controlling for each BPN, as an attempt to demonstrate the link between BTP and self-construal processes.

Furthermore, we investigated how these constructs are related to subjective well-being. We predicted that the satisfaction of BPN and higher ARS would lead to lower negative affect via BTP. Experiencing low levels of negative affect is one of the indicators of subjective wellbeing according to the hedonistic approach (Diener, Scollon, \& Lucas, 2009). Previous studies have demonstrated reliable relationships of BPN, ARS, and BTP with various indices of subjective well-being including negative affect and anxiety as well as the association of BPN and BTP. We reasoned that cultural and familial factors act as a foundation for BTP to develop, which, then, lead to higher subjective wellbeing. Such fundamental role of early learning experiences on time orientations is in line with the time perspective theory (Zimbardo \& Boyd, 1999). Trait anxiety was utilized as an index of general negative affect (Balsamo et al., 2013), and separate simple mediation analyses were conducted to assess the indirect effects of BPN and ARS on trait anxiety via the mediator of BTP.

\section{Method}

\subsection{Participants}

305 undergraduates (259 females, 46 males) from Istanbul Bilgi University with age ranging from 18 to $43(M=22.13, S D=2.82)$ were sampled from undergraduate courses through emails and announcements via convenience sampling. All participants were informed about the nature of the study and received course credit for their participation. 


\subsection{Measures}

\subsubsection{Zimbardo's time perspective inventory (ZTPI)}

A Turkish version of the ZTPI (Akirmak, unpublished manuscript) that consists of 56 items and is responded on a Likert scale ranging from 1 (very uncharacteristic) to 5 (very characteristic) was used. The scale measures participants' time orientation with five factor scores, Past Positive, Past Negative, Present Hedonistic, Present Fatalistic, and Future. Cronbach's alpha estimates were $0.85,0.80,0.79,0.67$, and 0.78 , respectively for $\mathrm{PN}, \mathrm{PP}, \mathrm{PH}, \mathrm{PF}$, and $\mathrm{F}$ in the current study.

A derived score, deviation from balanced time perspective (DBTP), was computed as an indicator of the BTP (Stolarski, Bitner, \& Zimbardo, 2011). DBTP scores were calculated as follows: obtained ZTPI factor scores were subtracted from the optimal factor scores and then squared; the sum of these squared deviations was computed; and, finally, the square root of this result was calculated. Higher DBTP scores indicate larger deviations from the balanced time perspective with zero indicating the optimal time perspective.

\subsubsection{Basic psychological needs scale (BPNS)}

This measure has 21 items rated on a scale ranging from 1 (not at all true) to 5 (very true), and assesses participants' satisfaction of the needs for autonomy, competence and relatedness (Kesici, Üre, Bozgeyikli, \& Sünbül, 2003). Higher scores indicate higher degree of need satisfaction. The internal consistency estimates were $0.75,0.69$, and 0.83 respectively for autonomy, competence, and relatedness in the current study.

\subsubsection{State-trait anxiety inventory (STAI)}

We assessed self-reported well-being with the trait anxiety scale of the STAI. The Turkish version (Öner \& Le Compte, 1983) has 20 items rated on a four point Likert scale. We assessed only the trait factor due to its relevance to stable characteristics. Higher scores indicate greater anxiety and negative affect. In the current study, internal reliability of STAI was 0.89 .

\subsubsection{Autonomous relatedness scale (ARS)}

ARS has 9 items responded on a scale ranging from 1 (strongly disagree) to 5 (strongly agree) (Kağıtçıbaş1, 2007). Items measure the extent to which participants agree that having close relationships restrains or is a threat to their autonomy. Higher scores indicate less of a conflict between autonomy and relatedness, and thus indicates a self-construal that favors both autonomy and close relationships. The scale had an internal consistency estimate of 0.76 in the current study.

\subsubsection{Hollingshead's four factor index (HFFI)}

Social economic status (SES) was assessed by the HFFI (Hollingshead, 1975). Each participant reported parents' education levels ranked from 1 to 7 and occupations ranked from 1 to 9 . Three authors of this paper independently rated self-reported occupations, and these ratings, together with the education level ratings, were used to compute SES scores. The agreement between raters was strong (0.96) as indicated by the intraclass correlation coefficient (ICC3), and an average of these ratings was used in the analysis. Socioeconomic status of the participants was relatively high.

\subsection{Procedure}

Data was collected online through an anonymous survey link. Participants first filled out the demographic information, then the questions assessing SES of their parents, and, finally, the aforementioned scales. The order of the scales was randomized for each participant.

\footnotetext{
${ }^{1}$ See supplementary materials.
}

\subsection{Statistical analyses}

All statistical analyses were performed using the R statistical software (R Development Core Team, 2017). There were very few missing observations $(<0.003)$, and were replaced by the item means for all scale questions except for the HFFI. The associations among TP, BPN, and ARS scores were investigated by computing Pearson correlation coefficients. A two-step hierarchical regression analysis was conducted to assess the relative contributions of the BPN and ARS on the DBTP scores, controlling for SES and gender. Finally, two simple mediation models that contained ARS or BPN as the predictors, DBTP as the mediator, and trait anxiety as the outcome variable were assessed. 95\% bias-corrected bootstrap confidence intervals for the direct and indirect effects were computed on 5000 bootstrap samples with the R package lavaan (Rosseel, 2012).

\section{Results}

\subsection{Descriptive analyses}

The means, standard deviations, and inter-correlations are shown in Table 1. The ZTPI factor scores showed similar pattern of correlations with the BPN and ARS scores. Specifically, PN and PF had negative, but $\mathrm{PP}, \mathrm{F}$, and $\mathrm{PH}$ had positive associations with these constructs. The only correlations that were not statistically significant were the associations of relatedness with F and PF. DBTP scores were negatively correlated with all three BPN factor scores and ARS scores, and the correlation coefficients were in the range of medium to large. Trait anxiety exhibited medium to large sized positive associations with DBTP, PN, and $\mathrm{PF}$, but medium to large sized negative associations with PP, autonomy, competence, relatedness, and ARS, and weak negative association with $\mathrm{PH}$.

\subsection{Regression analysis}

Multicollinearity, homoscedasticity, and linearity assumptions of regression were evaluated, and no problems were detected (Tabachnick \& Fidell, 2007). A multivariate outlier was eliminated based on the $\chi^{2}$ distributions of the Mahalanobis distance scores $(\alpha=0.001, d f=6$, $\chi^{2}=22.46$ ) (Tabachnick \& Fidell, 2007).

The results of the hierarchical regression analysis are shown in Table 2. Gender and SES scores did not predict DBTP scores at Step 1 $(F<1)$ or Step 2 . When the BPN factors and ARS were entered into the model at Step 2, the model explained $35 \%$ of variation in the DBTP scores with a statistically significant change in the $R^{2}, F(4$, $275)=38.01, p<.001$. Autonomy, competence, and ARS scores were significant predictors of the DBTP scores, but relatedness was not a significant predictor in the model.

\subsection{Mediation analyses}

In the first mediation model, the mediator, DBTP, was regressed on BPN to assess $a$, and trait anxiety was regressed on BPN and DBTP to assess $b$ and $c^{\prime}$, respectively. The same procedure was repeated for the second mediation model, which had ARS as the predictor variable (i.e., IV) instead of BPN. All variables were entered as a single score except for the BPN. Our focus was on the overall effect of the psychological need satisfaction, and, thus, BPN were entered into the model as a latent variable rather than separately testing each of the BPN factors. ${ }^{2} \mathrm{~A}$ reflective latent variable model was specified with relatedness, competence, and autonomy as indicators of BPN.

Following the standard conventions, the indirect effects of BPN and

\footnotetext{
${ }^{2}$ The mediation analyses involving each of the BPN as a predictor variable yielded similar results; see supplementary materials.
} 
Table 1

Means, standard deviations, and correlations of the variables.

\begin{tabular}{|c|c|c|c|c|c|c|c|c|c|c|c|c|c|c|}
\hline & M & SD & 1 & 2 & 3 & 4 & 5 & 6 & 7 & 8 & 9 & 10 & 11 & 12 \\
\hline 1. SES & 51.61 & 10.65 & - & & & & & & & & & & & \\
\hline 2. DBTP & 2.28 & 0.76 & 0.01 & - & & & & & & & & & & \\
\hline 3. Past negative & 3.04 & 0.74 & 0.00 & $0.75^{* *}$ & - & & & & & & & & & \\
\hline 4. Past positive & 3.55 & 0.66 & 0.02 & $-0.70^{* * *}$ & $-0.39 * *$ & - & & & & & & & & \\
\hline 5. Future & 3.54 & 0.53 & $-0.16^{* *}$ & $-0.31^{* *}$ & -0.04 & $0.19^{* *}$ & - & & & & & & & \\
\hline 6. Present fatalistic & 2.62 & 0.56 & -0.06 & $0.56^{* *}$ & $0.36^{* *}$ & -0.09 & $-0.33^{* *}$ & - & & & & & & \\
\hline 7. Present hedonistic & 3.43 & 0.49 & 0.01 & -0.10 & 0.03 & $0.18^{* *}$ & $-0.22^{* *}$ & $0.22^{* *}$ & - & & & & & \\
\hline 8. Trait anxiety & 44.80 & 9.12 & -0.05 & $0.66^{* * *}$ & $0.70^{* *}$ & $-0.42^{* *}$ & -0.09 & $0.32^{* *}$ & $-0.16^{* *}$ & - & & & & \\
\hline 9. Autonomy & 3.68 & 0.58 & 0.04 & $-0.59^{* *}$ & $-0.55^{* *}$ & $0.46^{* *}$ & $0.12^{*}$ & $-0.31^{* *}$ & $0.17^{* *}$ & $-0.66^{* *}$ & - & & & \\
\hline 10. Competence & 3.49 & 0.60 & 0.11 & $-0.40^{* * *}$ & $-0.33^{* *}$ & $0.27^{* * *}$ & $0.24^{* * *}$ & $-0.25^{* * *}$ & $0.21^{\text {** }}$ & $-0.50^{* *}$ & $0.54^{* * *}$ & - & & \\
\hline 11. Relatedness & 3.97 & 0.61 & 0.06 & $-0.46^{* *}$ & $-0.36^{* *}$ & $0.48^{* *}$ & 0.09 & -0.11 & $0.30^{* * *}$ & $-0.44^{* *}$ & $0.60^{* *}$ & $0.46^{* * *}$ & - & \\
\hline 12. ARS & 4.12 & 0.49 & $0.13^{*}$ & $-0.42^{* *}$ & $-0.34 * *$ & $0.28^{* *}$ & $0.13^{*}$ & $-0.36^{* *}$ & 0.09 & $-0.32^{* *}$ & $0.43^{* *}$ & $0.27^{* *}$ & $0.40^{* *}$ & - \\
\hline
\end{tabular}

Note. $N=283$ for SES; for all others $N=305$. SES = social economic status, DBTP = deviation from balanced perspective, ARS = autonomous-related self.

$* p<.05$.

** $p<.01$.

Table 2

Summary for hierarchical regression analysis for variables predicting DBTP scores.

\begin{tabular}{|c|c|c|c|c|c|c|}
\hline \multirow[t]{2}{*}{ Variable } & \multicolumn{3}{|c|}{ Model 1} & \multicolumn{3}{|c|}{ Model 2} \\
\hline & $B$ & $S E B$ & $\beta$ & $B$ & $S E B$ & $\beta$ \\
\hline Gender & 0.18 & 0.13 & 0.08 & 0.09 & 0.11 & 0.05 \\
\hline SES & 0.00 & 0.00 & 0.00 & 0.00 & 0.00 & 0.07 \\
\hline Autonomy & & & & -0.49 & 0.09 & $-0.37^{* * * *}$ \\
\hline Competence & & & & -0.17 & 0.07 & $-0.13^{*}$ \\
\hline Relatedness & & & & -0.10 & 0.08 & -0.08 \\
\hline ARS & & & & -0.26 & 0.08 & $-0.17^{* *}$ \\
\hline$R^{2}$ & & 0.01 & & & 0.36 & \\
\hline$F$ for change in $R^{2}$ & & 0.99 & & & $38.01^{* *}$ & \\
\hline$d f$ for $F$ change & & 2,279 & & & 4, 275 & \\
\hline
\end{tabular}

Note. Gender was coded as 1 female and 2 male. DBTP = deviation from balanced perspective, ARS = autonomous-related self.

$$
\begin{aligned}
& { }^{*} p<.05 . \\
& { }^{* *} p<.01 . \\
& { }^{* * *} p<.001 \text {. }
\end{aligned}
$$

ARS were operationalized by the effects of these variables on trait anxiety via DBTP $(a b)$ and were evaluated by examining whether the corresponding 95\% bias-corrected bootstrap confidence interval includes zero (Hayes, 2017). The results of the analyses are presented in Fig. 1 and Table 3. The confidence intervals of the indirect effects of BPN and ARS did not include zero; $a b=-3.60$ with $95 \%$ CI $[-5.22$, $-2.20]$, and $a b=-4.99$ with $95 \%$ CI $[-6.75,-3.45]$, respectively for BPN (Fig. 1a) and ARS (Fig. 1b). These findings suggest that DBTP mediates the relationships between BPN and trait anxiety, and ARS and trait anxiety.

\section{Discussion}

Research on the antecedent influences and a theory on the underlying mechanisms of BTP have been lacking. TP has been assumed to develop from learning experiences involving family and culture (Keough et al., 1999), and the present research evaluated the plausibility of this assumption. The ZTPI factors were related to the BPN and ARS, which, respectively, reflect the influence of cultural and familial processes. Correlations of the DBTP scores with BPN and ARS were in the predicted direction and were fairly large. The present findings extend Zhang et al.'s (2013) findings by showing that family dynamics, besides overall need satisfaction, is associated with the ZTPI factors. Furthermore, the regression analysis showed that ARS and the needs for autonomy and competence predicted BTP stressing the importance of both family dynamics and psychological need satisfaction. Surprisingly, relatedness was not a significant predictor, but ARS was, implying that relatedness alone, without autonomy, is not influential on the DBTP scores. Caution for studies utilizing a general BPN scale is warranted, because only autonomy and competence were significant predictors of DBTP.

As the main thesis of this paper, the extent to which BPN are satisfied is presumed to be one of the primary mechanisms supporting the BTP. Similarly, a specific form of self-construal, ARS, is also presumed to be crucial. ARS develops through family interactions and modeling that involve psychological interdependence and autonomy (Kagitcibasi, 2005). While ARS marks the influence of past family dynamics, BPN marks the influence of current social and cultural environment. Present findings support the aforementioned assumptions by demonstrating that satisfaction of the BPN and endorsement of ARS are related to BTP. With more restrictive social environments, psychological need satisfaction and optimal self-construal are not going to be fulfilled, which, in turn, disrupts the harmony in TP by creating a temporal disposition. An individual with a temporal disposition is likely to be insensitive to situational demands in his/her temporal categorization or interpretation of life events.

Present research underscores the importance of social and cultural dynamics in attempts to restore BTP, which have not received much attention in TP literature. A popular method to alleviate negative temporal cognitions is time perspective therapy (Sword, Sword, Brunskill, \& Zimbardo, 2014), however this approach focuses solely on the individual, is specific to PTSD, and neglects the broader sociocultural context. The needs that are essential for personal growth, and internal motivation and regulation of values and behavior, seem to be also essential for BTP, implying that without need satisfaction, an individual may not attain BTP. Similarly, having a BTP seems to depend on the early family interactions that favor the psychological rather than the utilitarian value of the children. Such experiences are likely to lead to an optimal self-construal, ARS, providing the essential mechanisms (i.e., family support, making autonomous decisions) to cope with future life experiences. Thus, considering these contextual factors provides a useful framework in understanding and reforming time orientations.

Present study also contributes to the theories of well-being by showing the roles of sociocultural and familial processes on trait anxiety through the mediational role of BTP. Higher psychological need satisfaction and higher scores on the ARS are associated with lower DBTP scores (i.e., higher BTP) leading to lower trait anxiety. The lower bounds of the confidence intervals of the indirect effects were all sufficiently distant from zero, indicating reliable effects. The present findings suggest an important, albeit neglected, connection between self-determination and time perspective theories by showing that less restrictive socio-cultural environments lead to higher subjective wellbeing through BTP. Results pertaining to the optimal self-construal warrant further research on the associations of other forms of self- 


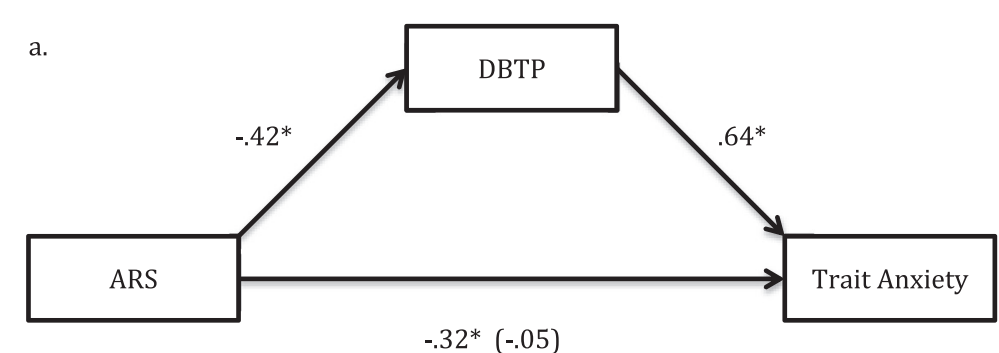

$-.32 *(-.05)$
Fig. 1. Standardized regression coefficients for the relationship between (a) ARS and trait anxiety, and (b) BPN and trait anxiety mediated by DBTP. The standardized regression coefficients between ARS and trait anxiety, and BPN and trait anxiety, controlling for DBTP, are in parentheses.

DBTP = deviation from balanced perspective, ARS = autonomous-related self, $\mathrm{BPN}=$ basic psychological needs. ${ }^{*} p<.001$.

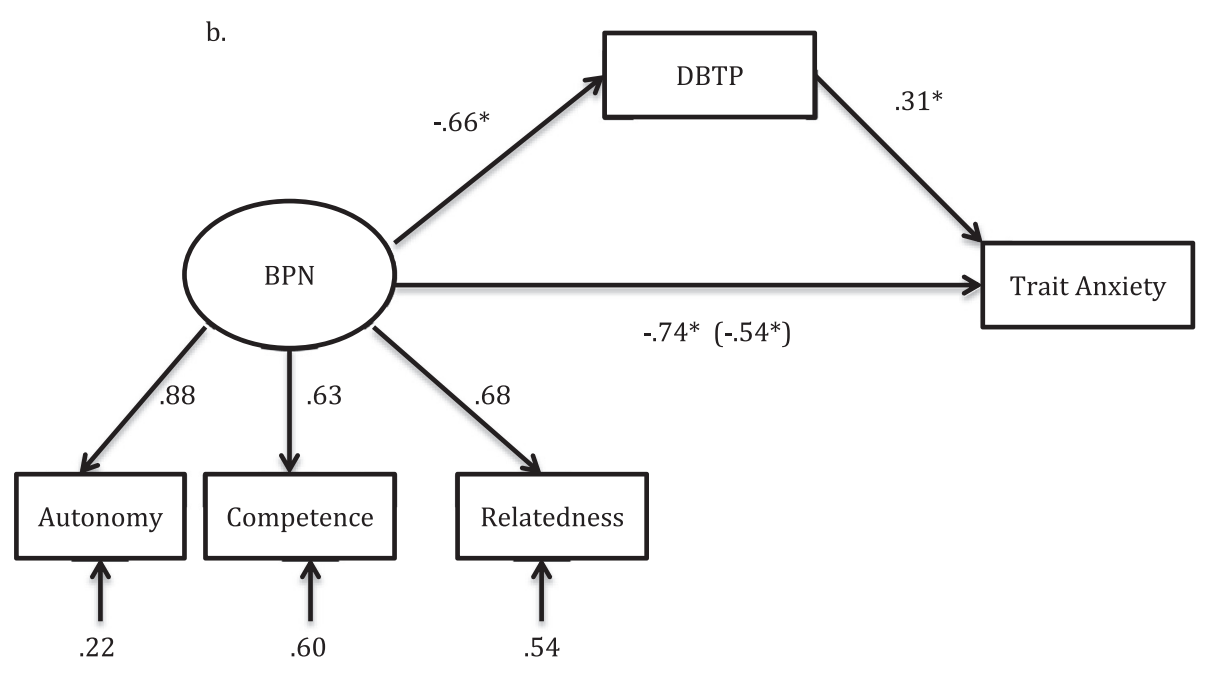

Table 3

Effects of ARS and BPN on trait anxiety via DBTP.

\begin{tabular}{|c|c|c|c|c|c|c|c|c|c|}
\hline \multirow[t]{2}{*}{ Independent variable } & \multicolumn{3}{|l|}{ Total } & \multicolumn{3}{|l|}{ Direct } & \multicolumn{3}{|l|}{ Indirect } \\
\hline & $B$ & $S E$ & $95 \% C I$ & $B$ & $S E$ & $95 \% C I$ & $B$ & $S E$ & $95 \% C I$ \\
\hline ARS & -5.94 & 1.01 & -8.01 to -4.05 & -0.95 & 0.97 & -2.79 to 0.96 & -4.99 & 0.84 & -6.75 to -3.45 \\
\hline BPN & -13.14 & 1.03 & -15.42 to -11.29 & -9.54 & 1.35 & -12.53 to -7.22 & -3.60 & 0.76 & -5.22 to -2.20 \\
\hline
\end{tabular}

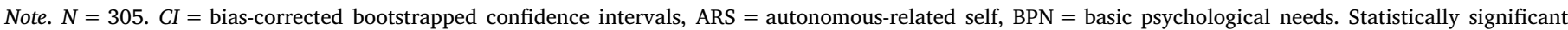
effects are printed in bold type.

construal and family dynamics with BTP. Similarly, the association between BPN and BTP naturally leads to further research questions on the potential relationship between BTP and regularity processes underlying goal pursuit.

There were several limitations of this study. Participants consisted mostly of young adults and women limiting the generalizability of the findings. Future studies can make use of positive indicators of subjective well-being such as satisfaction with life, happiness, and positive affect to extend the current findings on trait anxiety to other measures of self-reported well-being. The rationale of the mediation models was based on the time perspective theory and previously established predictors of subjective well-being. The correlational nature of the present cross-sectional study limits strong causal inferences. The validity of the present inferences can be bolstered by longitudinal studies that can better evaluate the direction of influence among the variables, specifically, BPN, ARS, BTP, and trait anxiety. As a final note, we see replications of the present findings in different cultures and in a more heterogeneous sample necessary in order to evaluate whether our findings generalize to other cultures and samples.

\section{Appendices. Supplementary files}

Supplementary data to this article can be found online at https:// doi.org/10.1016/j.paid.2018.11.008.

\section{References}

Akirmak, U. (2014). How is time perspective related to perceptions of self and of interpersonal relationships? The Spanish Journal of Psychology, 17, E92. https://doi.org/ 10.1017/sjp.2014.92.

Baard, P. P., Deci, E. L., \& Ryan, R. M. (2004). Intrinsic need satisfaction: A motivational basis of performance and well-being in two work settings. Journal of Applied Social Psychology, 34(10), 2045-2068.

Balsamo, M., Romanelli, R., Innamorati, M., Ciccarese, G., Carlucci, L., \& Saggino, A. (2013). The state-trait anxiety inventory: Shadows and lights on its construct validity. Journal of Psychopathology and Behavioral Assessment, 35(4), 475-486. https://doi. org/10.1007/s10862-013-9354-5.

Boniwell, I., Osin, E., Linley, A. P., \& Ivanchenko, G. V. (2010). A question of balance: Time perspective and well-being in British and Russian samples. The Journal of Positive Psychology, 5(1), 24-40.

Boniwell, I., \& Zimbardo, P. (2004). Balancing time perspective in pursuit of optimal functioning. In P. A. Linley, \& S. Joseph (Eds.). Positive psychology in practice (pp. 165178). New Jersey: John Wiley \& Sons.

Buttle, F. (1989). The social construction of needs. Psychology and Marketing, 6(3), 
197-210. https://doi.org/10.1002/mar.4220060304.

Carstensen, L. L., Isaacowitz, D. M., \& Charles, S. T. (1999). Taking time seriously: A theory of socioemotional selectivity. American Psychologist, 54(3), 165-181.

Chen, B., Vansteenkiste, M., Beyers, W., Boone, L., Deci, E. L., van der Kaap-Deeder, J., ... Ryan, R. M. (2015). Basic psychological need satisfaction, need frustration, and need strength across four cultures. Motivation and Emotion, 39(2), 216-236.

Church, A. T., Katigbak, M. S., Locke, K. D., Zhang, H., Shen, J., de Jesús Vargas-Flores, J., ... Mastor, K. A. (2013). Need satisfaction and well-being: Testing self-determination theory in eight cultures. Journal of Cross-Cultural Psychology, 44(4), 507-534.

Deci, E. L., \& Ryan, R. M. (2000). The 'what' and 'why' of goal pursuits: Human needs and the self-determination of behavior. Psychological Inquiry, 11(4), 227-268.

Deci, E. L., \& Ryan, R. M. (2012). Motivation, personality, and development within embedded social contexts: An overview of self-determination theory. In R. M. Ryan

(Ed.). The Oxford handbook of human motivation (pp. 85-107). New York, NY: Oxford University Press.

Diener, E., Scollon, C. N., \& Lucas, R. E. (2009). The evolving concept of subjective wellbeing: The multifaceted nature of happiness. In E. Diener (Ed.). Assessing well-being: The collected works of Ed Diener (pp. 67-100). New York, NY: Springer Science + Business Media. https://doi.org/10.1007/978-90-481-2354-4 4.

Drake, L., Duncan, E., Sutherland, F., Abernethy, C., \& Henry, C. (2008). Time perspective and correlates of wellbeing. Time \& Society, 17(1), 47-61. https://doi.org/10.1177/ $0961463 X 07086304$.

Hayes, A. F. (2017). Introduction to mediation, moderation, and conditional process analysis: A regression-based approach. New York, NY: Guilford Publications.

Hollingshead, A. B. (1975). Four factor index of social status. New Haven, CT: Yale University Press.

Holman, E. A., \& Zimbardo, P. G. (2009). The social language of time: The time perspective-social network connection. Basic and Applied Social Psychology, 31(2), 136-147. https://doi.org/10.1080/01973530902880415.

Jacobsen, T., Huss, M., Fendrich, M., Kruesi, M. J., \& Ziegenhain, U. (1997). Children's ability to delay gratification: Longitudinal relations to mother-Child attachment. The Journal of Genetic Psychology, 158(4), 411-426.

Kagitcibasi, C. (1996). The autonomous-relational self: A new synthesis. European Psychologist, 1, 180-186.

Kagitcibasi, C. (2005). Autonomy and relatedness in cultural context: Implications for self and family. Journal of Cross-Cultural Psychology, 36, 403-422.

Kağıtçıbașı, C. (2007). Family, self, and human development across cultures: Theory and applications. London: Lawrence Erlbaum Associates.

Kagitcibasi, C., \& Ataca, B. (2005). Value of children and family change: A three decade portrait from Turkey. Applied Psychology, 54(3), 317-337.

Kairys, A., \& Liniauskaite, A. (2015). Time perspective and personality. In M. Stolarski, N. Fieulaine, \& W. van Beek (Eds.). Time perspective theory: Review, research and application (pp. 99-113). Switzerland: Springer.
Keough, K. A., Zimbardo, P. G., \& Boyd, J. N. (1999). Who's smoking, drinking, and using drugs? Time perspective as a predictor of substance use. Basic and Applied Social Psychology, 21(2), 149-164.

Kesici, Ş., Üre, Ö., Bozgeyikli, H., \& Sünbül, A. M. (2003). Temel psikolojik ihtiyaçlar ölçeğinin geçerlik ve güvenirliği. VII. Ulusal PDR Kongresi Bildiri Özetleri Kitabı. Malatya: İnönü Üniversitesi.

Morsünbül, Ü. (2013). Benlik kurgularının ergenlerin yaşam doyumu ve depresyon düzeylerine olan etkisi. Klinik Psikiyatri Dergisi, 16(1), 18-26.

Ng, J. Y. Y., Ntoumanis, N., Thogersen-Ntoumani, C., Deci, E. L., Ryan, R. M., Duda, J. L., \& Williams, G. C. (2012). Self-determination theory applied to health contexts: A meta-analysis. Perspectives on Psychological Science, 7, 325-340. https://doi.org/10. $1177 / 1745691612447309$.

Öner, N., \& Le Compte, A. (1983). Durumluk-sürekli kaygi envanteri el kitabi (1st ed.). Istanbul: Bogaziçi Üniversitesi Matbaasi.

R Development Core Team (2017). R: A language and environment for statistical computing. Vienna, Austria: R Foundation for Statistical Computing. Retrieved from http://www. R-project.org/.

Rosseel, Y. (2012). Lavaan: An R package for structural equation modeling and more. Version 0.5-12 (BETA). Journal of Statistical Software, 48(2), 1-36.

Ryan, R. M., Patrick, H., Deci, E. L., \& Williams, G. C. (2008). Facilitating health behavior change and its maintenance: Interventions based on self-determination theory. European Health Psychologist, 10(1), 2-5.

Seginer, R. (2003). Adolescent future orientation: An integrated cultural and ecological perspective. Online Readings in Psychology and Culture, 6(1), 5.

Stolarski, M., Bitner, J., \& Zimbardo, P. G. (2011). Time perspective, emotional intelligence and discounting of delayed awards. Time \& Society, 20(3), 346-363.

Sword, R. M., Sword, R. K., Brunskill, S. R., \& Zimbardo, P. G. (2014). Time perspective therapy: A new time-based metaphor therapy for PTSD. Journal of Loss and Trauma, 19(3), 197-201.

Tabachnick, B. G., \& Fidell, L. S. (2007). Using multivariate statistics. Allyn \& Bacon/ Pearson Education.

Webster, J. D., \& Ma, X. (2013). A balanced time perspective in adulthood: Well-being and developmental effects. Canadian Journal on Aging/La Revue Canadienne Du Vieillissement, 32(4), 433-442. https://doi.org/10.1017/S0714980813000500.

Yildirim, P. K., Yildirim, E., Otrar, M., \& Şirin, A. (2015). Ergenlerde psikolojik dayanıklılık ile benlik kurgusu arasındaki ilişkinin incelenmesi. Eğitim Bilimleri Dergisi, 42(42), 277-297.

Zhang, J. W., Howell, R. T., \& Stolarski, M. (2013). Comparing three methods to measure a balanced time perspective: The relationship between a balanced time perspective and subjective well-being. Journal of Happiness Studies, 14(1), 169-184.

Zimbardo, P. G., \& Boyd, J. N. (1999). Putting time in perspective: A valid, reliable individual-differences metric. Journal of Personality and Social Psychology, 77(6), 1271-1288. https://doi.org/10.1037//0022-3514.77.6.1271. 